Article

\title{
Nectandra grandiflora By-Products Obtained by Alternative Extraction Methods as a Source of Phytochemicals with Antioxidant and Antifungal Properties
}

\author{
Daniela Thomas da Silva ${ }^{1}$, Rene Herrera ${ }^{2}$, Berta Maria Heinzmann ${ }^{3}$, Javier Calvo ${ }^{4}$ and \\ Jalel Labidi ${ }^{2, *(1)}$ \\ 1 Center of Rural Sciences, Federal University of Santa Maria, Ave. Roraima 1000, \\ Santa Maria 97105-900, Brazil; dthomasdasilva@gmail.com \\ 2 Biorefinery Processes Research Group, Department of Chemical and Environmental Engineering, \\ University of the Basque Country (UPV/EHU), Plaza Europa 1, 20018 Donostia, Spain; \\ renealexander.herrera@ehu.eus \\ 3 Department of Industrial Pharmacy, Federal University of Santa Maria, Ave. Roraima 1000, \\ Santa Maria 97105-900, Brazil; berta.heinzmann@gmail.com \\ 4 Chromatography and Mass Spectrometry Platform, CIC BiomaGUNE, Paseo Miramon 182, \\ 20009 San Sebastian, Spain; jcalvo@cicbiomagune.es \\ * Correspondence: jalel.labidi@ehu.es; Tel.: +34-94301-7178
}

Received: 26 December 2017; Accepted: 6 February 2018; Published: 9 February 2018

\begin{abstract}
Nectandra grandiflora Nees (Lauraceae) is a Brazilian native tree recognized by its durable wood and the antioxidant compounds of its leaves. Taking into account that the forest industry offers the opportunity to recover active compounds from its residues and by-products, this study identifies and underlines the potential of natural products from Nectandra grandiflora that can add value to the forest exploitation. This study shows the effect of three different extraction methods: conventional (CE), ultrasound-assisted (UAE) and microwave-assisted (MAE) on Nectandra grandiflora leaf extracts (NGLE) chemical yields, phenolic and flavonoid composition, physical characteristics as well as antioxidant and antifungal properties. Results indicate that CE achieves the highest extraction phytochemical yield (22.16\%), but with similar chemical composition to that obtained by UAE and MAE. Moreover, CE also provided a superior thermal stability of NGLE. The phenolic composition of NGLE was confirmed firstly, by colorimetric assays and infrared spectra and then by chromatographic analysis, in which quercetin-3-O-rhamnoside was detected as the major compound $(57.75-65.14 \%)$. Furthermore, the antioxidant capacity of the NGLE was not altered by the extraction methods, finding a high radical inhibition in all NGLE ( $>80 \%$ at $2 \mathrm{mg} / \mathrm{mL}$ ). Regarding the antifungal activity, there was observed that NGLE possess effective bioactive compounds, which inhibit the Aspergillus niger growth.
\end{abstract}

Keywords: forest residues; phenolic compounds; natural antioxidants; quercitrin; value-added by-products

\section{Introduction}

Innovative and environmental-friendly approaches are the key to increase the profitability, economic viability and sustainability in the forest industry by optimizing the process in order to obtain high-valued products (bio/chemicals and biomaterials). Forest residues (bark, foliage, branches) represent a renewable feedstock that has been used for many years as a combustible material, however, the development of by-products is an essential path for forest valorization [1]. Tree bark and foliage constitute a little explored but promising source of natural compounds or phytochemicals (in the form 
of pure or as mixtures/extracts) that could be used as active ingredients for agronomic, cosmetic, food additives, pharmaceutical and in nutraceutical formulations [1,2]. Several techniques have been described for extracting active natural compounds from low-cost raw material [3]. These procedures include the so-called heating systems, such as traditional Soxhlet and heat reflux extraction $[4,5]$, ultrasound-assisted extraction $[6,7]$ and microwave-assisted extraction $[8,9]$, as well as supercritical fluid and pressurized extraction [10,11] or the combination of these extraction techniques [12].

Conversely, many natural matrix products are thermally unstable and may degrade under thermal extraction conditions [12]. Moreover, large consumption of solvents, energy and lengthy extraction time are some drawbacks that should also be taken into account. The ideal extraction procedure has to retain the maximum of the bioactive constituents in a shortest processing time with low economic costs [13] and low environmental impact [14]. Additionally, the extraction methods should be simple, safer for users and with a level of automation for industrial application [14,15]. In general, the selection of an appropriate extraction procedure depends on the type of compound to be extracted, as well as the development of the technique [16]. Several studies reported the efficiency of microwave-assisted extraction (MAE) and ultrasound-assisted extraction (UAE) for increasing the content of polyphenols $[9,17]$. In MAE, the microwave energy is used to heat the polar solvents in contact with solid samples and thus, recovering the target compounds [18]. Likewise, the UAE involves a superficial disrupt of plant tissue, allowing the penetration of solvent into cell walls through the acoustic cavitation [19].

It is worth noting that the Brazilian flora is a rich source of phytochemicals, aromas and bioactive compounds of medicinal and pharmaceutical importance, as well the fine chemicals segment [20]. Nectandra is one of the largest genera of Lauraceous family that includes ca. 120 tree species and more than 190 reported different types of natural substances with several therapeutic applications [21]. Nectandra grandiflora Nees, commonly known as "canela-amarela" or "canela-fedida", is a medium-sized tree (10-15 m) endemic of Brazilian Atlantic forest and Cerrado biomes [22]. This species presents a moderately heavy and naturally durable wood recommended for timbering and furniture [23]. On the other hand, there are not enough scientific studies regarding the environmental-friendly and cost-effective technologies to recover phytochemicals (e.g., phenolic compounds) from Nectandra grandiflora leaves. Ribeiro et al. [24] extracted flavonoid glycosides (natural antioxidants) and neoliganans from the tree foliage by conventional heating processing (Soxhlet). On these grounds, the present study aims to address the unexplored potential of Nectandra grandiflora co-products describing the phenolic composition, thermal behavior, antioxidant and antifungal properties of its leaf extracts obtained by alternative green processes (MAE and UAE).

\section{Results and Discussion}

\subsection{Extraction Yields and Phytochemicals Contents}

Extraction yield refers to the percentage of ethanolic extract obtained from a dried plant sample through an extraction technique [17]. The three extraction methods applied on Nectandra grandiflora leaves showed significantly different yields of phytochemicals (Table 1).

The conventional Soxhlet (CE) method presented the highest yield (22.16 g DW/100 g dried plant), followed by ultrasound-assisted (UAE) and microwave-assisted extraction (MAE). The highest yield achieved by conventional extraction compared to ultrasound- and microwave-assisted methods can be explained by the application of heat for a longer period. However, the processing time used in ultrasound and microwave heating methods was significantly shorter (30 $\mathrm{min})$ than for the conventional one and taking the energy consumption into account, UAE and MAE appear as favorable extraction methods for Nectandra grandiflora leaves. Our findings are in accordance with Mustapa et al. [25], who reported a superior yield of Clinacanthus nutans extracts by CE compared to MAE. According to Chirinos et al. [26], after $60 \mathrm{~min}$, increasing extraction time did not significantly improve the phytochemical yield and may increasing the risk of phenolic oxidation (alterations in color, aroma and product quality). 
Table 1. Effect of extraction method on the phytochemical yields, total phenolic (TPC) and flavonoid (FLC) contents of Nectandra grandiflora Nees leaf extracts.

\begin{tabular}{cccc}
\hline \multicolumn{2}{c}{ Extraction } & \multirow{2}{*}{ TPC (mg GaE/g DW) } & FLC (mg QE/g DW) \\
\cline { 1 - 2 } Method & Yield (g DW/100g Dried Plant) & & \\
\hline CE & $22.16 \pm 1.18^{\mathrm{a}}$ & $279.00 \pm 7.32^{\mathrm{a}}$ & $150.85 \pm 0.71^{\mathrm{a}}$ \\
UAE & $13.99 \pm 2.58^{\mathrm{b}}$ & $254.94 \pm 7.58^{\mathrm{b}}$ & $114.50 \pm 0.71^{\mathrm{b}}$ \\
MAE & $8.21 \pm 2.74^{\mathrm{c}}$ & $229.62 \pm 1.85^{\mathrm{c}}$ & $123.83 \pm 3.60^{\mathrm{b}}$ \\
F & 28.32 & 62.55 & 22.40 \\
$p$ & $<0.001$ & $<0.001$ & 0.002 \\
MSD & 2.28 & 10.18 & 5.47 \\
\hline
\end{tabular}

Lower case letters indicate significant differences among the extraction methods for the same column by Tukey test $(p<0.05)$. CE: Conventional Soxhlet extraction; UAE: Ultrasound-assisted extraction; MAE: Microwave-assisted extraction; DW: Extract based on dried weight; GaE: Equivalent gallic acid; QE: Equivalent quercetin; MSD: Minimum Significant Difference.

In this work, the three evaluated extraction methods were able to recover high contents of total phenolic compounds, flavonoid and condensed tannins. However, we detected that the values determined in the extracts depended significantly on the process applied (Table 1). The CE extract presented higher values of total phenolic and flavonoid contents (279 mg GaE/g DW and $150.85 \mathrm{mg}$ $\mathrm{QE} / \mathrm{g}$ DW, respectively) than UAE and MAE extracts. Considering the composition of natural sources of polyphenols and flavonoid compounds, as well as their chemical structures and properties, an universal extraction procedure is not feasible and a specific method must be optimized for each natural bioactive compound $[27,28]$. Currently, some alternative techniques such as extraction under pressure $\left(\mathrm{N}_{2}\right)$ or enzymatic extraction in combination with UAE and MAE have been applied to increase phenolic yields from plant matrices $[29,30]$.

\subsection{FTIR Analysis}

Leaf extracts exhibited similar absorption bands in FTIR spectra but with slight differences in the extract obtained by CE. The spectra profiles are presented in Figure 1 and the assignments are given in Table S1.
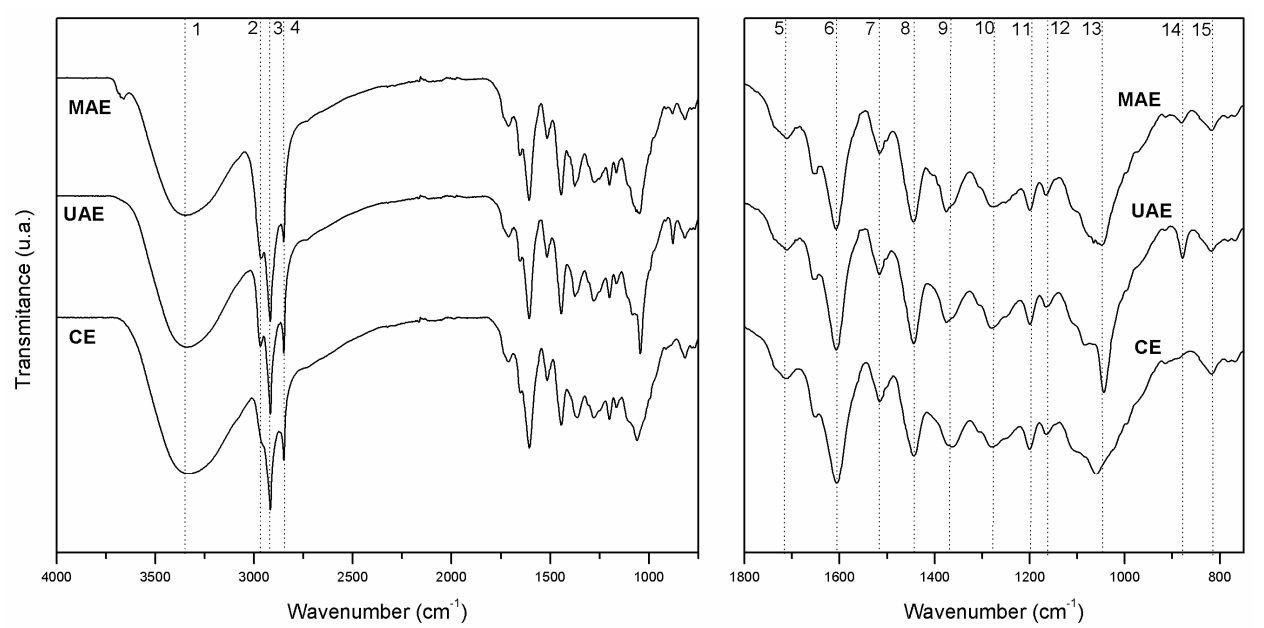

Figure 1. FTIR spectra of leaf extracts obtained from Nectandra grandiflora, by conventional Soxhlet extraction (CE), ultrasound-assisted extraction (UAE) and microwave-assisted extraction (MAE). Wavenumber range $4000-800 \mathrm{~cm}^{-1}$ (Left) and fingerprint region $1800-750 \mathrm{~cm}^{-1}$ (Right); band assignments are shown in Table S1. 
Analysis of the FTIR spectra ranging from 3400 to $3200 \mathrm{~cm}^{-1}$ shows the sum of different vibrational bands of $-\mathrm{OH}$ groups. The elongated $\mathrm{U}$ shape around this region is characteristic of alcoholic and phenolic compounds [31,32]. The region of $2945-2845 \mathrm{~cm}^{-1}$ is composed by the overlapping of the $\mathrm{CH}_{2}$, and $\mathrm{CH}_{3}$ stretching asymmetric and symmetric vibrations; possibly derived from carbohydrates [33].

However, these first regions analysed do not present conclusive features to identify the nature of the phytochemicals. Several authors have described the FTIR spectra fingerprinting region $\left(1800-750 \mathrm{~cm}^{-1}\right)$ because the target functional groups appear primarily in this range [25]. The weak peak at $1709 \mathrm{~cm}^{-1}$ shows the presence of the carbonyl group, possibly due to dimeric saturated acids [31]. The signals detected in the range $1615-1440 \mathrm{~cm}^{-1}$ (peaks 6-8) are assigned to aromatic ring stretching vibrations. A strong and intense peak at $1606 \mathrm{~cm}^{-1}$ corresponds to within-ring skeletal stretching, alongside with the stretching of the $\mathrm{C}=\mathrm{C}-\mathrm{C}$ aromatic bond that appears at $1515 \mathrm{~cm}^{-1}$.

The peak in the region of $1375-1361 \mathrm{~cm}^{-1}$ is assigned to the hydroxyl in-plane bending of primary and secondary alcohols [31,34]. Furthermore, Nectandra grandiflora extracts also show bands in the $1277-1271 \mathrm{~cm}^{-1}$ region, which correspond to the $\mathrm{C}-\mathrm{O}$ asymmetrical stretching vibration arising from the pyran-derived ring structure of flavonoids [33]. The peak around $1200 \mathrm{~cm}^{-1}$ is associated with phenol $\mathrm{C}-\mathrm{OH}$ stretches.

The 1154-1046 $\mathrm{cm}^{-1}$ region (peak 13) can be assigned to the $\mathrm{C}-\mathrm{H}$ in-plane deformation of aromatic compounds [33]. The extract obtained by UAE exhibited a strong and intense peak, while the other extracts only exhibit shoulders in this region. Finally, the aromatic $\mathrm{C}-\mathrm{H}$ out-of-plane bending vibration region between 920 and $750 \mathrm{~cm}^{-1}$ mostly shows signals of low intensity [32]. The extract obtained by ultrasound technique shows a medium-intensity signal at $878 \mathrm{~cm}^{-1}$ corresponding to the deformation of the $\mathrm{C}-\mathrm{H}$ bond in a substituted meta-diaromatic compound [35]. This signal was lower for the MAE extract and did not appear at all in the CE extract. Another low-intensity peak at $816 \mathrm{~cm}^{-1}$ can be seen in the FTIR spectra of all extracts.

The presence of peaks due to hydroxyl and carbonyl vibrations indicates that there are some polar compounds in the Nectandra grandiflora foliage extracts, such as flavonoids, neolignans and phenolic acids. These results are in agreement with those found by the total phenolic and flavonoid contents in this study and other scientific studies [24,36].

\subsection{LC-UV/ESI-HR-MS and MALDI/MS/MS Analysis}

In the LC-MS and MALDI/MS/MS analysis of Nectandra grandiflora leaf extracts, six compounds were detected based on their retention time, UV (wavelength of maximum absorbance) and mass spectra and MS fragmentation parameters. The molecular mass of the compounds was obtained from their positive ion electrospray mass spectra (ESI-MS), which showed the corresponding protonated pseudomolecular ions as well as the sodium adduct ions (parent ions). Table 2 lists the major $(>5 \%)$ compounds detected in Nectandra grandiflora extracts.

Table 2. Phenolic compounds detected in the leaf extracts obtained from Nectandra grandiflora Nees by LC-UV/ESI-HR-MS in the positive mode.

\begin{tabular}{|c|c|c|c|c|c|c|c|}
\hline CE & & & & & & & \\
\hline Proposed Compound & Peak & $t_{R}(\min )$ & $\lambda_{\max }(\mathrm{nm})$ & MW & {$[\mathrm{M}+\mathrm{Na}]^{+}(\mathrm{m} / \mathrm{z})$} & Fragment Ions $(\mathrm{m} / \mathrm{z})$ & Peak Area (\%) \\
\hline Myricetin-rhamnoside & 1 & 10.17 & $256.93 ; 351.93$ & 464 & 487.1861 & $319.1163 ; 273.2263$ & 11.26 \\
\hline Quercetin-rhamnoside & 2 & 11.72 & $255.93 ; 349.93$ & 448 & 471.1797 & $303.1064 ; 325.1030$ & 65.32 \\
\hline Kaempferol-rhamnoside & 3 & 12.96 & 263.93 & 432 & 455.1926 & $\begin{array}{c}\text { 218.2257; } 287.1182 ; \\
304.2944\end{array}$ & 5.13 \\
\hline Unidentified & 6 & 19.98 & 253.93 & 250 & 273.2414 & $\begin{array}{c}\text { 219.3682; 149.1013; } \\
137.0943\end{array}$ & 15.57 \\
\hline Total identified & & & & & & & 81.71 \\
\hline \multicolumn{8}{|l|}{ MAE } \\
\hline Proposed Compound & Peak & $t_{R}(\min )$ & $\lambda_{\max }(\mathrm{nm})$ & MW & {$[\mathrm{M}+\mathrm{Na}]^{+}(m / z)$} & Fragment Ions $(\mathrm{m} / \mathrm{z})$ & Peak Area (\%) \\
\hline Myricetin-rhamnoside & 1 & 10.14 & $258.93 ; 352.93$ & 464 & 487.1981 & $\begin{array}{c}319.1164 ; 273.2266 \\
341.1031\end{array}$ & 9.95 \\
\hline
\end{tabular}


Table 2. Cont.

\begin{tabular}{|c|c|c|c|c|c|c|c|}
\hline MAE & & & & & & & \\
\hline Quercetin-rhamnoside & 2 & 11.69 & $255.93 ; 340.93$ & 448 & 471.1819 & $303.1085 ; 325.1035$ & 62.54 \\
\hline Kaempferol-rhamnoside & 3 & 12.93 & 263.93 & 432 & 455.1905 & $\begin{array}{c}\text { 287.1170; } 218.2304 ; \\
309.1042\end{array}$ & 5.50 \\
\hline Unidentified & 6 & 19.98 & 254.93 & 250 & 273.2419 & $219.3695 ; 149.1015$ & 19.58 \\
\hline Total identified & & & & & & & 77.99 \\
\hline \multicolumn{8}{|l|}{ UAE } \\
\hline Proposed Compound & Peak & $t_{R}(\min )$ & $\lambda_{\max }(\mathrm{nm})$ & MW & {$[\mathrm{M}+\mathrm{Na}]^{+}(m / z)$} & Fragment Ions $(\mathrm{m} / \mathrm{z})$ & Peak Area (\%) \\
\hline Myricetin-rhamnoside & 1 & 10.14 & $256.93 ; 348.93$ & 464 & 487.1881 & $\begin{array}{c}\text { 319.1158; } 273.2258 ; \\
341.1027\end{array}$ & 9.77 \\
\hline Quercetin-rhamnoside & 2 & 11.69 & $255.93 ; 349.93$ & 448 & 471.1833 & 303.1102; 325.1038 & 61.18 \\
\hline Kaempferol-rhamnoside & 3 & 12.93 & 263.93 & 432 & 455.1806 & $\begin{array}{c}\text { 287.1170; } 218.2305 \\
304.2939\end{array}$ & 5.11 \\
\hline Unidentified & 6 & 19.98 & 255.00 & 250 & 273.2429 & $\begin{array}{c}220.2213 ; 149.1024 \\
137.0951\end{array}$ & 20.83 \\
\hline Total identified & & & & & & & 76.06 \\
\hline
\end{tabular}

The base peaks are in bold; CE: Conventional Soxhlet extraction; UAE: Ultrasound-assisted extraction; MAE: Microwave-assisted extraction.

All extracts presented a similar phenolic profile (Figure 2) with some differences in the estimated percentages of the compounds. More than $76 \%$ of the total chemical composition was established, achieving $81.71 \%$ in the conventional method. The compounds identified are glycosylated flavonols, of which quercetin rhamnoside (quercitrin) was the most abundant in the extract obtained by the conventional method (65.32\%). Kaempferol rhamnoside (afzelin) (11.26-9.77\%) and myricetin rhamnoside (myricitrin) $(<6 \%)$ were also detected. Figure S2 shows the MS fragmentation of the peaks 1,2 and 3 obtained through MALDI/MS/MS analysis, where is possible to see the fragmentation of glycosides by loss of the mass corresponding to rhamnose $(\approx 146 \mathrm{Da})$.
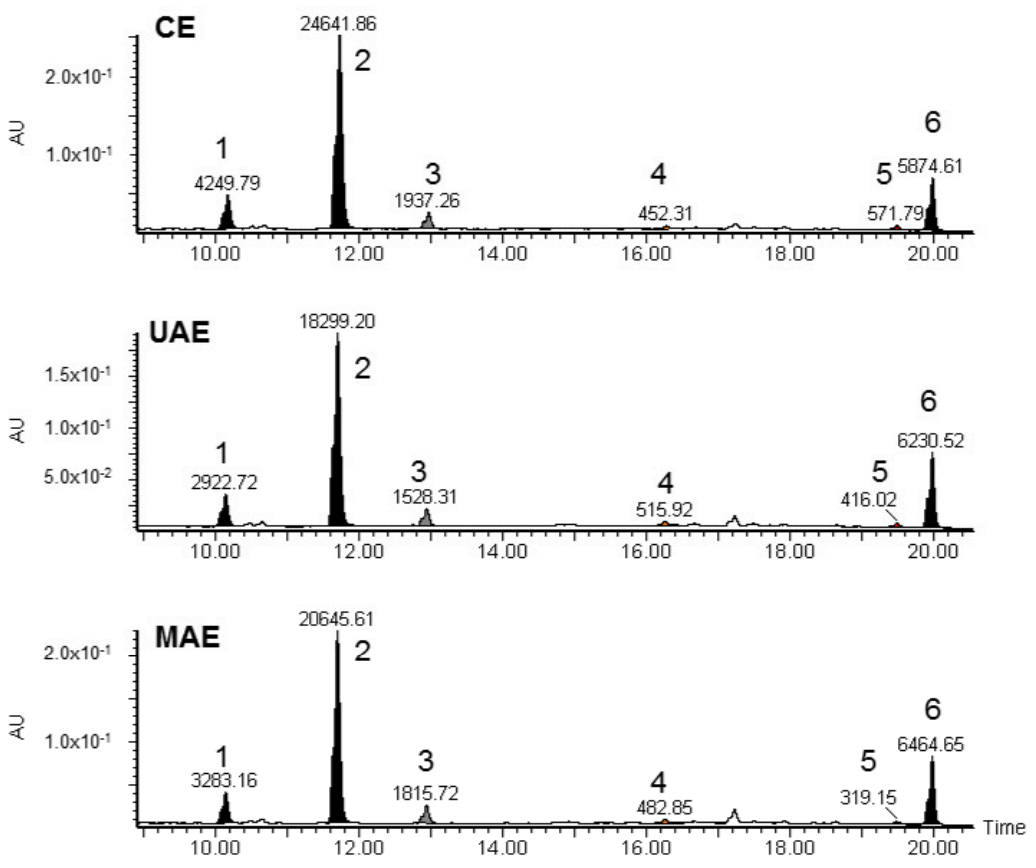

Figure 2. LC-UV chromatograms at $280 \mathrm{~nm}$ of the Nectandra grandiflora extracts obtained by conventional Soxhlet extraction (CE), ultrasound-assisted extraction (UAE) and microwave-assisted extraction (MAE). For peak identification, see Table 2 .

The peak numbers 4-6 were not identified by the LC-MS and MALDI/MS/MS techniques, but taking into account the UV spectrum of peak 6 (maximum absorbance in the 251-255 nm range) 
and MW data (250 MW), we hypothesized that this peak could correspond to a low molecular weight substance, such as a polyalcohol or a phenolic acid. Besides, according to Rijke et al. [37], flavonoids display a typical UV spectrum with a first absorbance maximum in the $240-285 \mathrm{~nm}$ range and a second one in the $300-550 \mathrm{~nm}$ range, as exhibited by quercitrin and myricitrin.

In previous studies, the compounds quercitrin and afzelin were identified in the ethanolic leaf extract from a Nectandra grandiflora specimen collected in São Paulo, Brazil [24,36]. Moreover, Ribeiro et al. [24] found protocatechuic acid, a naturally occurring phenolic acid, as constituent of Nectandra grandiflora leaves. Other phenolic compounds such as neolignan licarin B [38] and burchellin [24] were isolated from Nectandra grandiflora leaves and fruits, respectively.

\subsection{TG/DTG Profiles}

Thermal analysis was carried out as a first step to characterize the decomposition stages and thermal stability of Nectandra grandiflora extracts in the absence of parallel reactions. The TG/DTG curves of all extracts exhibited similar decomposition patterns, as displayed in Figure 3.
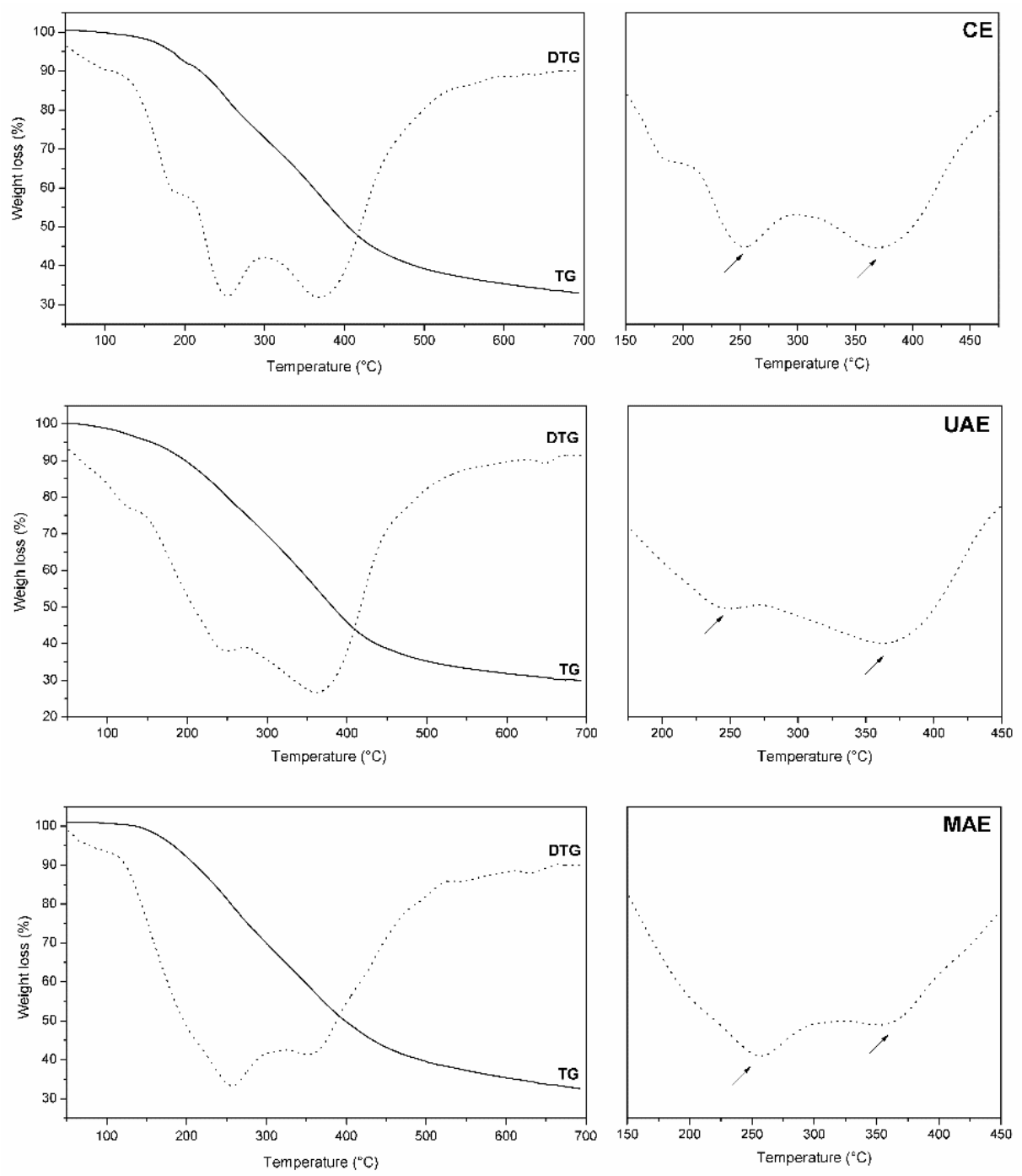

Figure 3. TG/DTG profiles of Nectandra grandiflora extracts obtained by different techniques. CE: Conventional Soxhlet extraction; UAE: Ultrasound-assisted extraction; MAE: Microwave-assisted extraction. The arrows indicate the temperatures where the greatest mass loss occurred. 
During the extraction process, several bioactive substances from different class can be recovered from the plant raw material. Besides phenolic compounds, polar solvents (such as ethanol) can also extract lipids, fats, terpenoids, sugars and chlorophylls [36].

DTG curves from all extracts showed a slight mass loss within the temperature range $50-180{ }^{\circ} \mathrm{C}$, which was mainly caused by water desorption [39] and decomposition of terpenoid derivatives (volatile compounds) [40]. All thermograms showed two main degradation peaks indicating the main organic matter losses [41]. The first one was between 240 and $270{ }^{\circ} \mathrm{C}$ (peak 1), and the second between 340 and $380{ }^{\circ} \mathrm{C}$ (peak 2). Peak 1 may be attributed to thermal breakdown of aliphatic structures and glycosylated aromatic compounds (such as quercetin-3-O-rhamnoside detected by the LC-MS technique), and peak 2 was associated with the degradation of more stable compounds [39-44].

At the end of the TG process (about $700{ }^{\circ} \mathrm{C}$ ), the solid residues for CE, UAE and MAE were 32.76, 29.85 and $31.88 \%$, respectively. The percentage of residual mass in the CE sample can be attributed to the higher presence of phenolic substances (78.66\% estimated by LC-MS), which tend to become fixed carbon during the pyrolysis process [45].

\subsection{Solubility Results}

The solubility of the obtained extracts was evaluated using an organic solvent and then analysing the optical images formed by the solutions (Figure S1). We detected similar physical characteristics (solubility) of the obtained extracts. The solution prepared with CE sample presented an average concentration of $3.98 \times 106$ particles $/ \mu \mathrm{L}$, while UAE sample presented $3.49 \times 106$ particles $/ \mu \mathrm{L}$ and MAE, $3.31 \times 106$ particles $/ \mu \mathrm{L}$. No pronounced variation in the average diameter of the undissolved particles was observed among the extract solutions, only a slight variation between MAE and CE samples was detected $(4.9 \mu \mathrm{m}$ and $5.1 \mu \mathrm{m}$, respectively). The applied method is a novel fast assessment that provides useful information such as particle size and organic solubilization, which are important characteristics in the natural materials subject and regarding environmental issues [46].

\subsection{Antioxidant Activity}

Regarding the antioxidant activities, Nectandra grandiflora leaf extracts were able to inhibit both DPPH and ABTS free radicals, in comparison with quercetin, used as positive control. The antioxidant effect in a concentration-response relationship was verified in all samples and the corresponding equations are displayed in Figure 4.

All ethanolic extracts showed good scavenging activities to reduce the stable radical DPPH to yellow-colored 2,2-diphenyl-1-picrylhydrazine. Besides, the results indicate that there are no significant differences between the Nectandra grandiflora extract samples at the same tested concentration. At the highest concentration $(2 \mathrm{mg} / \mathrm{mL})$, the DPPH radical inhibition reached $85.59 \%$ with CE and UAE, and $82.39 \%$ with MAE. Quercetin reached $86.85 \%$ of inhibition at $2 \mathrm{mg} / \mathrm{mL}$, significantly different in all Nectandra grandiflora samples. In the ABTS radical cation decoloration assay, the leaf extracts have a similar inhibition rate to that found against DPPH radical. No statistical differences among any of the samples were detected at $2 \mathrm{mg} / \mathrm{mL}$ (Figure 4B). At the lowest concentration, UAE presented better values than the $C E$ and MAE procedures; however, these values were lower than those achieved by the positive control was. Considering the $R^{2}$ values among the tests, the observed differences can be due to the reaction environment (alcoholic or hydro-alcoholic), the solubility of the main compounds in each reaction medium as well as the variable activity of antioxidants in reducing the pre-formed radical cation radical $\left(\mathrm{ABTS}^{\bullet+}\right)$ to $\mathrm{ABTS}$ [47].

Our findings illustrate the antioxidant capacity of Nectandra grandiflora leaves was weakly affected by the extraction protocol [17]. The positive results detected can be assigned to the phytochemicals present in the leaf extracts. Probably the most active natural phytochemicals in the Nectandra grandiflora extracts are from the flavonoid chemical class, since they present specific structural characteristics that promote antioxidant activity. The $o$-catechol group on the B-ring as occurs in quercetin derivatives, the major phytochemicals detected in this study, is the most important of them [48]. Moreover, the same 
partial structure appears in protocatechuic acid [49], already described in Nectandra grandiflora [24]. Other flavonoids with chemical characteristics can contribute the antioxidant properties, such as the three hydroxyl groups on the B-ring (present in myricetin derivatives) and the $\alpha, \beta$-unsaturated carbonyl system on the C-ring [45]. These characteristics confer great stability to the phenolic radical as soon it is formed after one $\mathrm{H}$ radical donation to DPPH [24,50,51].

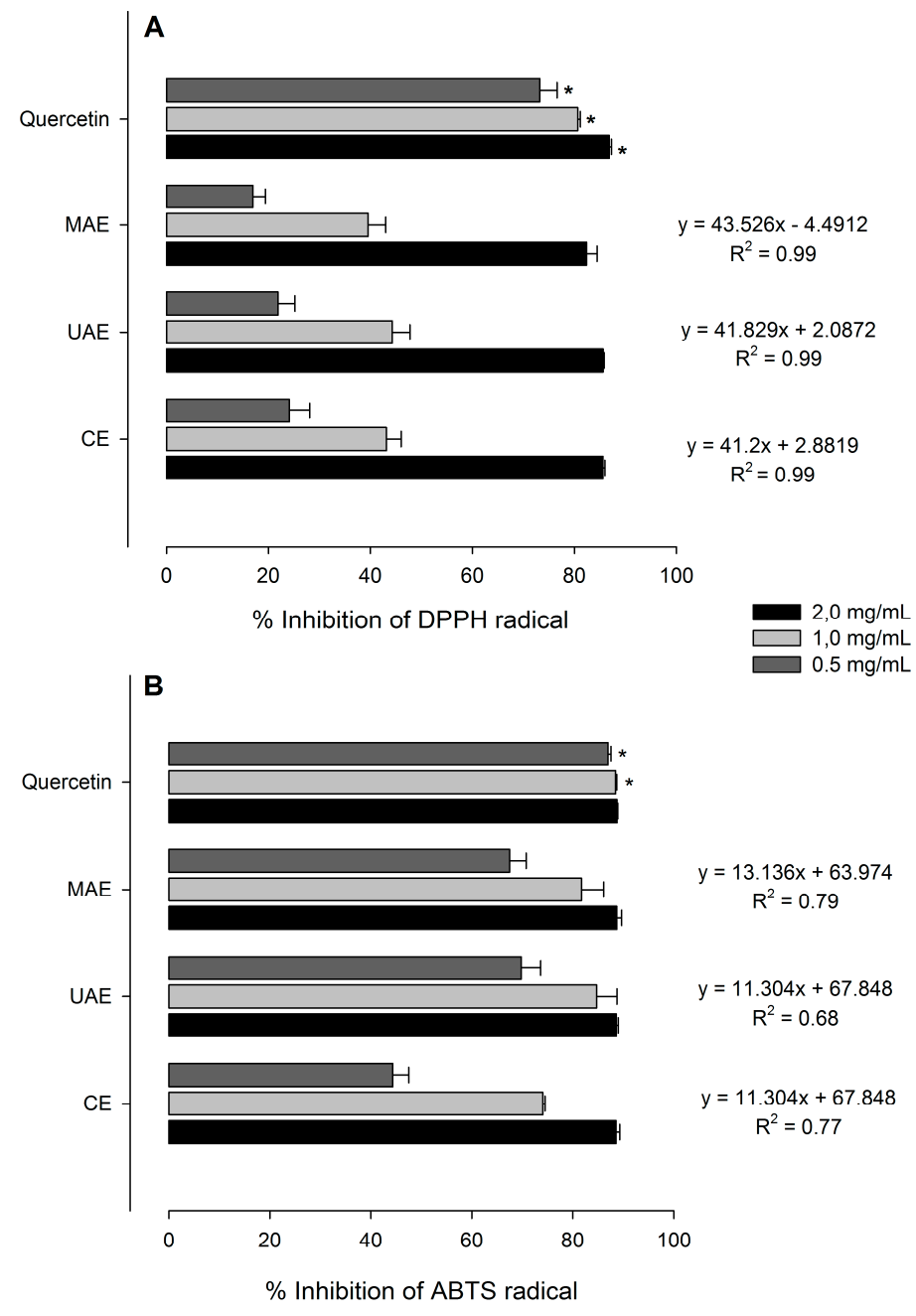

Figure 4. Antioxidant capacities on DPPH (A) and ABTS (B) free radicals of leaf extracts obtained from Nectandra grandiflora. * Indicate significant differences among the extraction methods and quercetin for the same concentration by Tukey test $(p<0.05)$. CE: Conventional Soxhlet extraction; UAE: Ultrasoundassisted extraction; MAE: Microwave-assisted extraction; Quercetin: Positive control.

\subsection{Antifungal Activity}

The methods used to measure the antifungal effect of the extracts were designed to determine both the efficacy of compounds to prevent fungal growth and as a method to assess the susceptibility of the growth of molds to impregnated materials. Results from exposure of Aspergillus. niger to various concentrations of Nectandra grandiflora extracts are displayed in Figure 5, which in turn were contrasted with a positive control (amphotericin B) and with a negative control (without product).

As indicated in Figure 5, the leaf extracts did not inhibit fungal growth dose-dependently according to the evaluated methods. In Figure 5A, all extracts tested at $100 \mathrm{mg} / \mathrm{mL}$ of concentration were effective in controlling the fungal growth (growth intensity $=1$ ), by visual assessment (without contact with the center of the dish). 
A
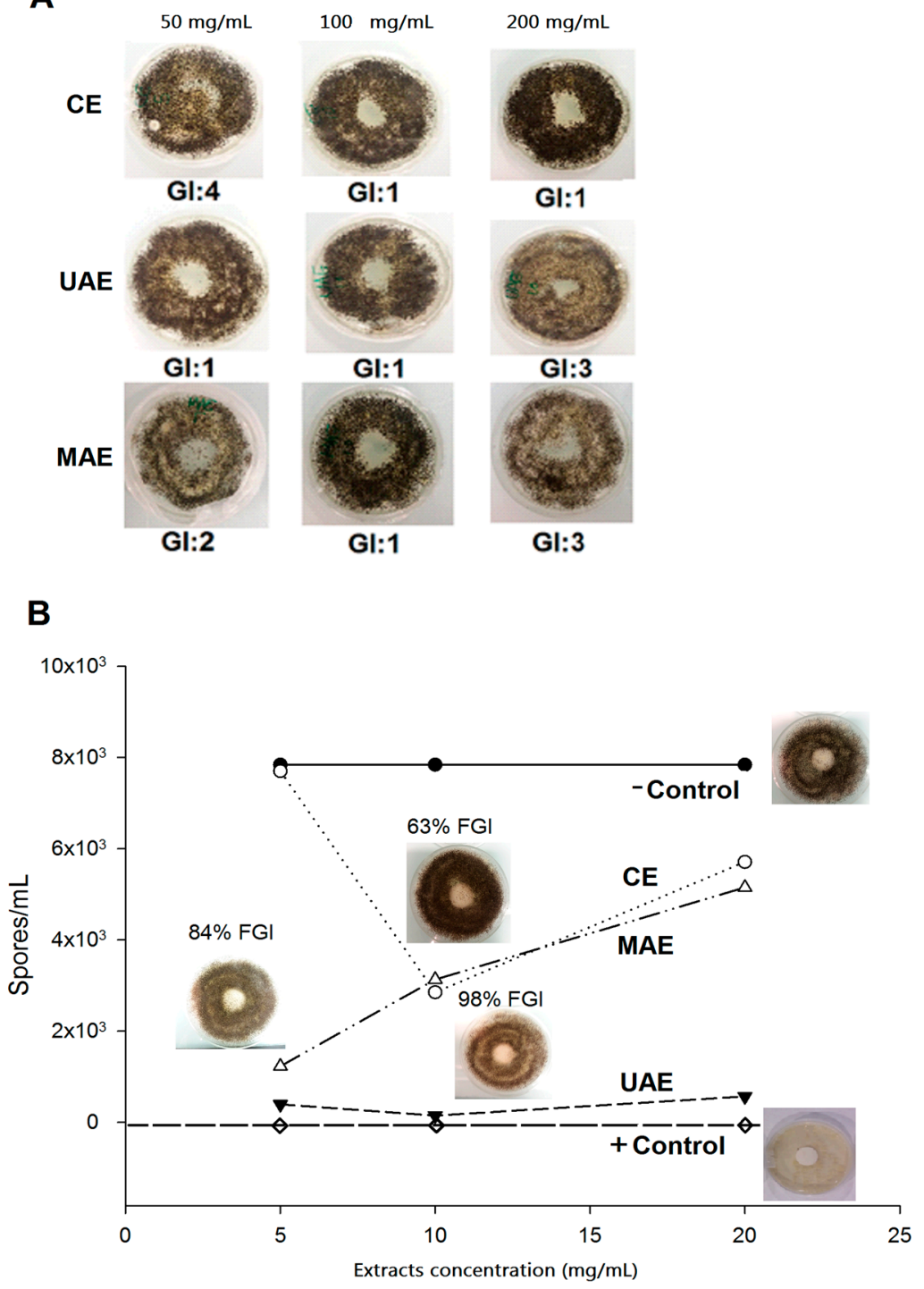

Figure 5. Antifungal activity of Nectandra grandiflora extracts against Aspergillus niger by the potato dextrose agar method (A) and cellulose pellets method (B). GI: Growth intensity; FGI: Fungal growth inhibition; CE: Conventional Soxhlet extraction; UAE: Ultrasound-assisted extraction; MAE: Microwave-assisted extraction.

At $200 \mathrm{mg} / \mathrm{mL}$, the samples of CE were more efficient than those samples from UAE and MAE (growth intensity $=3$ ). A similar trend of fungal growth inhibition was observed with the second method (cellulose pellets; Figure 5B). The CE sample at $100 \mathrm{mg} / \mathrm{mL}$ inhibited $63 \%$ of fungal growth and UAE extract reached to a maximum of $98 \%$ at the final concentration of $100 \mathrm{mg} / \mathrm{mL}$, compared to non-treated control. Regarding the MAE sample, higher fungal inhibition (84\%) was achieved at a concentration of $50 \mathrm{mg} / \mathrm{mL}$.

To the best of our knowledge, there are no reports regarding the inhibitory potential of Nectandra grandiflora against Aspergillus niger. Previously, the antifungal activity of the Nectandra grandiflora leaf essential oil against wood-rot fungi was reported [40], where it was able to inhibit Pycnoporus sanguineus and Gloeophyllum trabeum growth at concentration of $5 \mu \mathrm{l} / \mathrm{mL}$. From these findings and from Magro et al.'s study [52], which examined the Anthemis nobilis leaf extract and found an inhibitory effect at $920 \mathrm{mg} / \mathrm{mL}$ against Aspergillus niger, we can affirm that the Nectandra grandiflora leaves possess potential antifungal constituents. 


\section{Materials and Methods}

\subsection{Plant Material}

Aerial parts of Nectandra grandiflora were collected from a natural habitat in Jaguari County, in the South of Brazil $\left(29^{\circ} 26^{\prime} \mathrm{S}\right.$ and $\left.54^{\circ} 40^{\prime} \mathrm{W}\right)$, in December 2013. Leaves were separated from the branches and fractionated in order to achieve the ethanolic extracts. A voucher specimen, identified by Solon Jonas Longhi, is archived under number 13162 at the Herbarium of Biology Department (SMDB, Federal University of Santa Maria, Brazil).

\subsection{Preparation of Ethanolic Extracts}

Leaves were air-dried at room temperature $\left(25^{\circ} \mathrm{C}\right)$, milled (Willey mill, Swedesboro, NJ, USA) and then extracted with ethanol $96 \%$, which is regarded as a generally recognized as safe (GRAS) solvent, at a raw material: solvent ratio of 1:20, by means of ultrasound-assisted extraction (UAE), microwave-assisted extraction (MAE) or conventional solvent extraction (CE) [17]. The extraction procedures were as follows: the UAE was carried out using an ultrasonic cleaner (Elmasonic S 70H, Elma Schmidbauer GmbH, Singen, Germany) at a power of $750 \mathrm{~W}$ and $50{ }^{\circ} \mathrm{C}$ and MAE was done with a CEM Discover microwave (CEM Corporation, Matthews, NC, USA) at $50{ }^{\circ} \mathrm{C}$ and power controlled by the equipment. Both UAE and MAE were performed for $30 \mathrm{~min}$ using ca. $5 \mathrm{~g}$ per replicate $(n=3)$. The CE was performed using a Soxhlet apparatus (Hermanos Álamo, Madrid, Spain) (ca. 15 g per replicate; $n=3$ ) until the total exhaustion of the plant material ( $24 \mathrm{~h})$.After the extraction period, the ethanolic extracts were cooled to room temperature and filtered. The solvent was removed at $50{ }^{\circ} \mathrm{C}$ under reduced pressure on a rotary evaporator and then the extraction yields were calculated by weighing the extracts obtained per each 100 grams of dried plant based on dried weight (DW).

\subsection{Total Phenolic Content}

The total phenolic content of Nectandra grandiflora leaf extracts was measured spectrophotometrically (Jasco V-630 spectrophotometer, Jasco Deutschland GmbH, Hamburg, Germany) by the FolinCiocalteu's method, as described by Cândido et al. [53], with some modifications. Dried extracts were solubilized in methanol $(0.5 \mathrm{mg} / \mathrm{mL})$, aliquots of these samples $(0.25 \mathrm{~mL})$ were mixed with $2.5 \mathrm{~mL}$ of distilled water, and $0.25 \mathrm{~mL}$ of the Folin-Ciocalteu reagent (previously diluted 1:10 with distilled water). After $5 \mathrm{~min}, 0.25 \mathrm{~mL}$ of sodium carbonate $(75 \mathrm{mg} / \mathrm{mL}$ in aqueous solution) was added and adjusted to $10 \mathrm{~mL}$ with distilled water. The mixtures were kept at room temperature for $60 \mathrm{~min}$ and the absorbance was measured at $725 \mathrm{~nm}$. Gallic acid $(0-0.2 \mathrm{mg} / \mathrm{mL})$ was used for calibration of a standard curve. The calibration curve was linear at $R^{2}=0.99$, and the results were expressed as mg of gallic acid equivalents per gram of dried weight (mg GaE/g DW). Triplicate measurements were taken and data were presented as mean \pm standard deviation.

\subsection{Flavonoid Content}

The flavonoid content of the extracts was determined by the $\mathrm{AlCl}_{3}$ technique [54] using a spectrophotometer (Jasco V-630). The results were expressed as mg of quercetin equivalents (QE) per $g$ DW from a standard calibration curve $\left(0-0.1 \mathrm{mg} / \mathrm{mL} ; R^{2}=0.99\right)$.

\subsection{Infrared Analysis}

In order to determine the functional groups presents in CE, UAE and MAE samples, Fourier Transform Infrared (FTIR) analysis was applied. Infrared spectra were recorded in a Perkin Elmer spectrophotometer (Waltham, MA, USA) at a resolution of $4 \mathrm{~cm}^{-1}$ over the $700-4000 \mathrm{~cm}^{-1}$ range using milled samples [55]. 


\subsection{LC-UV/ESI-HR-MS Analysis}

LC-UV/ESI-HR-MS analysis was carried out on a UPLC system (Waters ACQUITY UPLC System, Milford, MA, USA) equipped with a UV-Vis photodiode array detector and coupled to a mass spectrometer. UV spectra were recorded between 200 and $500 \mathrm{~nm}$ and the UV detection was measured at $280 \mathrm{~nm}\left(100 \%\right.$ correspond to sum of area of six detected peaks in each sample). An Acquity $\mathrm{C}_{18}$ column $(100 \times 2.1 \mathrm{~mm}$ i.d., $1.7 \mu \mathrm{m})$ at $40{ }^{\circ} \mathrm{C}$ was used to chromatography separation. The mobile phase was constituted by two solvents: water-formic acid $(0.1 \%, \mathrm{~A})$ and methanol (B), and the gradient elution had the following profile: $0-25 \mathrm{~min} 95 \% \mathrm{~A}, 25-27.7 \mathrm{~min} 1 \% \mathrm{~A}$ and $27.7-30 \mathrm{~min} 5 \% \mathrm{~A}$ at a flow rate of $300 \mu \mathrm{L} / \mathrm{min}$. Extract samples were prepared at $200 \mu \mathrm{g} / \mathrm{mL}$ in methanol:water (1:1) and $10 \mu \mathrm{L}$ aliquots were injected for analysis.

Mass spectra were acquired using a LCT Premier XE (Waters) equipped with an electrospray ionization (ESI) source operated in the positive $\mathrm{W}$ mode. The experimental parameters were set as follows: the capillary voltage was $750 \mathrm{~V}$; cone voltage was $50 \mathrm{~V}$; and ions were recorded in the range of $m / z$ 100-1000. In order to obtain exact mass measurements, leukine-enkephalin was used as lockmass reference compound $(m / z 556.2771)$. Data acquisition and analysis were performed using Waters MassLynx 4.1 software (Waters Corporation, Milford, MA, USA).

\subsection{MALDI-TOF/TOF MS Analysis}

MALDI-TOF/TOF mass analysis were performed on an Ultraflextreme III time-of-flight mass spectrometer equipped with a pulsed Nd:YAG laser $(355 \mathrm{~nm})$ and controlled by FlexControl 3.3 software (Bruker Daltonics, Bremen, Germany). The acquisitions (total of 4000-5000) were carried out in positive reflector ion mode with pulse duration of $70 \mathrm{~ns}$, laser fluence of $35 \%$ and laser frequency of $1 \mathrm{kHz}$. Laser intensity was set marginally above the threshold of ionization to avoid fragmentation (less than $10 \%$ for all the cases). Fragmentation of the molecules were performed with a LIFT cell voltage of $19 \mathrm{kV}$ and a final acceleration voltage set at $29.3 \mathrm{kV}$ and the parent mass ions were assigned manually (monoisotopic peak $\mathrm{M}+\mathrm{Na}$ ). Ion source 1, 2 and lens voltages were set at 7.56, 6.86 and 3.52. $5 \mu \mathrm{L}$ of sample (extract at $200 \mu \mathrm{g} / \mathrm{mL}$ in Water $/ \mathrm{MeOH}$ ) was mixed with $10 \mu \mathrm{L}$ of $\alpha$-Cyano-4-hydroxycinnamic acid matrix solution $(10 \mathrm{mg} / \mathrm{mL}$ in Methanol Water 1/1). $1 \mu \mathrm{L}$ of the analyte/matrix mixture was deposited onto the polished stainless-steel MALDI target plate and was allowed to dry.

All the peaks were detected as sodium/potassium adducts. The acquired data was processed (baseline substraction and normalized) using the Bruker FlexAnalysis 3.3 software (Bruker Daltonics, Bremen, Germany).

\subsection{Thermogravimetric Analysis}

Thermal behavior of Nectandra grandiflora extracts (CE, UAE and MAE) was measured in a nitrogen atmosphere using a TGA/SDTA RSI analyser (Mettler Toledo, L'Hospitalet de Llobregat, Barcelona, Spain) according to Herrera et al. [55]. For the quantitative calculations, the response factors between the weight gain (TG) and the mass loss rate (DTG) were determined.

\subsection{Solubility Measurement of Extracts}

To investigate the extracts solubility in organic solvents, CE, UAE and MAE samples were diluted in dimethyl sulfoxide (DMSO) at a concentration of $10 \mathrm{mg} / \mathrm{mL}$ and the solubility was analyzed by a Cellometer ${ }^{\circledR}$ Mini Vision equipment (Nexcelom Bioscience LLC, Lawrence, MA, USA). Each extract solution was precisely pipetted $(0.02 \mathrm{~mL})$ into a Nexcelom disposable counting chamber to determinate the concentration of undissolved extracts (particles $/ \mu \mathrm{L}$ ) and the particles sizes (average size from 1 to $35 \mu \mathrm{m}$ ) by the Cellometer ${ }^{\circledR}$ Mini Counter Software (Nexcelom Bioscience LLC, Lawrence, MA, USA, Software version 1.2.3.3). 


\subsection{Antioxidant Activities}

\subsubsection{DPPH Assay}

The DPPH (2,2-diphenyl-1-picrylhydrazyl) radical scavenging activity of the extracts was carried out according to Dudonné et al. [56] on a Jasco V-630 Spectrophotometer. An aliquot (0.02 mL) of leaf extracts at different concentrations was added to $2 \mathrm{~mL}$ of DPPH methanolic solution $(0.06 \mathrm{mM})$ and kept at room temperature for $30 \mathrm{~min}$. The absorbance was measured at $517 \mathrm{~nm}$ and quercetin was utilized as positive control.

\subsubsection{ABTS Assay}

The antioxidant capacity was also evaluated by ABTS spectrophotometric assay [47]. Extract samples were diluted in methanol at different concentrations and an aliquot $(0.04 \mathrm{~mL})$ was added to $2 \mathrm{~mL}$ of ABTS radical solution. This solution was prepared by mixing ABTS $(7 \mathrm{mM})$ and potassium persulfate $(2.45 \mathrm{mM})$ in water for $12-16 \mathrm{~h}$ at room temperature in a light-free environment. Then, the absorbance of radical solution was adjusted to $0.60 \pm 0.02$ at $734 \mathrm{~nm}$ in ethanol: water (1:1). Each extract sample was measured between 1 and $6 \mathrm{~min}$.

\subsection{Determination of Antifungal Activity against Aspergillus niger}

The fungus Aspergillus niger (Tiegh MB284309 CBS-KNAW, Utrecht, The Netherlands) was cultured on potato dextrose agar (PDA) for 7 days at $27 \pm 1.5^{\circ} \mathrm{C}$ and used in this assay. Extracts samples were diluted in DMSO at final concentrations of 50, 100 and $200 \mathrm{mg} / \mathrm{mL}$, and then evaluated by two methods: (1) extracts pipetted directly in PDA medium and inoculated with fungal strain; and (2) extracts impregnated in cellulose pellets and exposed to fungal strain in PDA.

In the first method, an aliquot $(40 \mu \mathrm{L})$ of each extract was pipetted to the center of a Petri dish filled with PDA, and around that was inoculated a fungal strain. The Petri dishes were sealed and incubated at $27 \pm 1.5^{\circ} \mathrm{C}$ (Selecta Medilow climatic chamber, JP Selecta S.A., Barcelona, Spain) for 7 days. After incubation time, we determined the growth intensity (GI) by visual assessment using a numerical scale according to ISO 846, as displayed in Table 3. Three repetitions of each extracts and control (without extracts) were prepared.

Table 3. Visual assessment of growth intensity according to ISO 846.

\begin{tabular}{cc}
\hline Growth Intensity (GI) & Evaluation \\
\hline 0 & No growth apparent under magnification \\
1 & No visible growth but visible under magnification \\
2 & Visible growth up to $25 \%$ coverage \\
3 & Visible growth up to $50 \%$ coverage \\
4 & Visible growth up to $75 \%$ coverage \\
5 & Heavy growth covering more than $75 \%$ of the studied area \\
\hline
\end{tabular}

In parallel, cellulose pellets $(\varnothing=10 \mathrm{~mm})$ were soaked with $5 \mu \mathrm{L}$ of each extract set and placed on Petri dishes with PDA $(10 \mathrm{~mL})$ and $0.4 \%$ streptomycin. Each PDA dish was inoculated with a spore suspension $\left(1 \times 10^{6}\right.$ spores $\left./ \mathrm{mL}\right)$ and incubated at $27 \pm 1.5^{\circ} \mathrm{C}$ for 7 days. Subsequently, pellets were removed from Petri dishes and washed with sterile Ringer's solution (Sigma-Aldrich-96724, St. Louis, MI, USA). The solution was stained (Lactophenol blue) and homogenized to count the spores concentration on the pellets with a Cellometer ${ }^{\circledR}$ Mini automated cell counter by placing $20 \mu \mathrm{L}$ of each spore solution inside counting chambers and using Cellometer ${ }^{\circledR}$ Mini software for the analysis. The fungal growth inhibition (FGI \%) was calculated as concentration of spores (conidia) per mL, according to the following Equation (1): 


$$
\text { FGI }(\%)=\frac{C g-T g}{C g} \times 100
$$

where, $C g$ is the average spores concentration in the control sample and $T g$ is the average concentration in the treated one [57].

\subsection{Statistical Procedure}

The results are expressed as the mean of three measurements \pm standard deviation. Normality (Shapiro-Wilk) and Equal Variance (Levene) tests were performed before the statistical approach. Analysis of variance (ANOVA) was conducted for the values of total phenolic, flavonoid and tannin contents, as well as for antioxidants data, followed by Tukey test. The differences with $p<0.05$ were considered significant.

\section{Conclusions}

The experimental results indicated that ultrasound- and microwave-assisted extraction techniques were effective to recover bioactive compounds from Nectrandra grandiflora leaves. Despite the fact that higher phytochemical contents were achieved by conventional extraction, the chemical composition, thermal stability and antioxidant activity did not present great differences to that found with the alternative green techniques. Besides, microwave- and ultrasound-assisted are timesaving extraction processes with lower energy consumption comparing to the Soxhlet method; however, it is necessary to optimize the ultrasound and microwave process conditions to increase the phytochemical yields. Furthermore, Nectandra grandiflora by-products could be an interesting source of active compounds for the natural antioxidants and antifungal market.

Supplementary Materials: The Supplementary Materials are available online.

Acknowledgments: This research was financially supported by the Department of Education of Basque Government (IT1008-16) and by Conselho Nacional de Desenvolvimento Científico e Tecnológico (CNPq process 454447 / 2014-0). Authors would like to thanks the CNPq for research grants received by Berta Maria Heinzmann, Ph.D. scholarship (process 203796/2014-4) granted to Daniela Thomas da Silva and the Basque Government for scholarship of young researchers training granted to Rene Herrera.

Author Contributions: Daniela Thomas da Silva, Berta Maria Heinzmann and Jalel Labidi conceived and designed the experiments; Daniela Thomas da Silva prepared the ethanolic extracts and analyzed the total phenolic content and antioxidant capacity; Javier Calvo prepared the LC-UV/ESI-HR-MS and MALDI-TOF/TOF MS analysis; Rene Herrera determined the antifungal activity; Daniela Thomas da Silva and Rene Herrera analyzed the TGA, FT-IR and solubility; Daniela Thomas da Silva and Rene Herrera wrote the article.

Conflicts of Interest: The authors declare no conflict of interest.

\section{References}

1. Devappa, R.K.; Rakshit, S.K.; Dekker, R.F.H. Forest biorefinery: Potential of poplar phytochemicals as value-added co-products. Biotechnol. Adv. 2015, 33, 681-716. [CrossRef] [PubMed]

2. Romani, A.; Pinelli, P.; Ieri, F.; Bernini, R. Sustainability, innovation, and green chemistry in the production and valorization of phenolic extracts from Olea europaea L. Sustainability 2016, 8, 1002-1012. [CrossRef]

3. Balasundram, N.; Sundram, K.; Samman, S. Phenolic compounds in plants and agri-industrial by-products: Antioxidant activity, occurrence, and potential uses. Food Chem. 2006, 99, 191-203. [CrossRef]

4. Yang, Y.; Chen, H.; Lin, C.; Chu, W.; Lo, H. Species distribution and drug susceptibilities of Candida isolates in TSARY 2010. Diagn. Microbiol. Infect. Dis. 2013, 76, 182-186. [CrossRef] [PubMed]

5. Pan, X.; Niu, G.; Liu, H. Comparison of microwave-assisted extraction and conventional extraction techniques for the extraction of tanshinones from Salvia miltiorrhiza bunge. Biochem. Eng. J. 2002, 12, 71-77. [CrossRef]

6. Hemwimol, S.; Pavasant, P.; Shotipruk, A. Ultrasound-assisted extraction of anthraquinones from roots of Morinda citrifolia. Ultrason. Sonochem. 2006, 13, 543-548. [CrossRef] [PubMed] 
7. Rodríguez-Pérez, C.; Quirantes-Piné, R.; Fernández-Gutiérrez, A.; Segura-Carretero, A. Optimization of extraction method to obtain a phenolic compounds-rich extract from Moringa oleifera Lam leaves. Ind. Crops Prod. 2015, 66, 246-254. [CrossRef]

8. Zhang, B.; Yang, R.; Liu, C. Microwave-assisted extraction of chlorogenic acid from flower buds of Lonicera japonica Thunb. Sep. Purif. Technol. 2008, 62, 480-483. [CrossRef]

9. Dahmoune, F.; Nayak, B.; Moussi, K.; Remini, H.; Madani, K. Optimization of microwave-assisted extraction of polyphenols from Myrtus communis L. leaves. Food Chem. 2015, 166, 585-595. [CrossRef] [PubMed]

10. Castro-Vargas, H.I.; Rodríguez-Varela, L.I.; Ferreira, S.R.; Parada-Alfonso, F. Extraction of phenolic fraction from guava seeds (Psidium guajava L.) using supercritical carbon dioxide and co-solvents. J. Supercrit. Fluids 2010, 51, 319-324. [CrossRef]

11. Monrad, J.K.; Howard, L.R.; King, J.W.; Srinivas, K.; Mauromoustakos, A. Subcritical solvent extraction of anthocyanins from dried red grape pomace. J. Agric. Food Chem. 2010, 58, 2862-2868. [CrossRef] [PubMed]

12. Wei, M.; Yang, Y.; Chiu, H.; Hong, S. Development of a hyphenated procedure of heat-reflux and ultrasound-assisted extraction followed by RP-HPLC separation for the determination of three flavonoids content in Scutellaria barbata D. Don. J. Chromatogr. B 2013, 940, 126-134. [CrossRef] [PubMed]

13. Wang, J.; Lu, H.D.; Muhammad, U.; Han, J.Z.; Wei, Z.H.; Lu, Z.X.; Bie, X.M.; Lu, F.X. Ultrasound-assisted extraction of polysaccharides from Artemisia selengensis Turcz and its antioxidant and anticancer activities. J. Food Sci. Technol. 2016, 53, 1025-1034. [CrossRef] [PubMed]

14. Vilkhu, K.; Mawson, R.; Simons, L.; Bates, D. Applications and opportunities for ultrasound assisted extraction in the food industry-A review. Innov. Food Sci. Emerg. Technol. 2008, 9, 161-169. [CrossRef]

15. Zhang, Z.; Wang, X.; Li, J.; Wang, G.; Mao, G. Extraction and free radical scavenging activity of polysaccharide from 'Anji Baicha' (Camellia sinensis (L.) O. Kuntze). Int. J. Biol. Macromol. 2016, 84, 161-165. [CrossRef] [PubMed]

16. Wijngaard, H.; Hossain, M.B.; Rai, D.K.; Brunton, N. Techniques to extract bioactive compounds from food by-products of plant origin. Food Res. Int. 2012, 46, 505-513. [CrossRef]

17. Nguyen, V.T.; Bowyer, M.C.; Vuong, Q.V.; Altena, I.A.; Scarlett, C.J. Phytochemicals and antioxidant capacity of Xao tam phan (Paramignya trimera) root as affected by various solvents and extraction methods. Ind. Crops Prod. 2015, 67, 192-200. [CrossRef]

18. Delazar, A.; Nahar, L.; Hamedeyazdan, S.; Sarker, S.D. Microwave-assisted extraction in natural products isolation. Methods Mol. Biol. 2012, 864, 89-115. [PubMed]

19. Wang, L.; Li, D.; Bao, C.; You, J.; Wang, Z.; Shi, Y.; Zhang, H. Ultrasonic extraction and separation of anthraquinones from Rheum palmatum L. Ultrason. Sonochem. 2008, 15, 738-746. [CrossRef] [PubMed]

20. Vieira, R.F.; Bizzo, H.R.; Deschamps, C. Genetic resources of aromatic plants from Brazil. Isr. J. Plant Sci. 2010, 58, 263-271. [CrossRef]

21. Grecco, S.S.; Lorenzi, H.; Tempone, A.G.; Lago, J.H.G. Update: Biological and chemical aspects of Nectandra genus (Lauraceae). Tetrahedron Asymmetry 2016, 27, 793-810. [CrossRef]

22. Lorenzi, H. Árvores Brasileiras: Manual de Identificação e Cultivo de Plantas Arbóreas Nativas do Brasil, 2nd ed.; Instituto Plantarum: Nova Odessa, Brazil, 2002.

23. Lorenzi, H. Árvores Brasileiras: Manual de Identificação e Cultivo de Plantas Arbóreas Nativas do Brasil, 3rd ed.; Instituto Plantarum: Nova Odessa, Brazil, 2009.

24. Ribeiro, A.B.; Bolzani, V.D.S.; Yoshida, M.; Santos, L.S.; Eberlin, M.N.; Silva, D.H.S. A new neolignan and antioxidant phenols from Nectandra grandiflora. J. Braz. Chem. Soc. 2005, 16, 526-530. [CrossRef]

25. Mustapa, A.N.; Martin, Á.; Mato, R.B.; Cocero, M.J. Extraction of phytocompounds from the medicinal plant Clinacanthus nutans Lindau by microwave-assisted extraction and supercritical carbon dioxide extraction. Ind. Crops Prod. 2015, 74, 83-94. [CrossRef]

26. Chirinos, R.; Rogez, H.; Campos, D.; Pedreschi, R.; Larondelle, Y. Optimization of extraction conditions of antioxidant phenolic compounds from mashua (Tropaeolum tuberosum Ruíz \& Pavón) tubers. Sep. Purif. Technol. 2007, 55, 217-225.

27. Madja, M.H.; Rajaei, A.; Bashi, D.S.; Mortazavi, S.A.; Bolourian, S. Optimization of ultrasonic-assisted extraction of phenolic compounds from bovine pennyroyal (Phlomidoschema parviflorum) leaves using response surface methodology. Ind. Crops Prod. 2014, 57, 195-202. 
28. Vuong, Q.V.; Hiruna, S.; Roach, P.D.; Bowyer, M.C.; Phillips, P.A.; Scarlett, C.J. Effect of extraction conditions on total phenolic compounds and antioxidant activities of Carica papaya leaf aqueous extracts. J. Herb. Med. 2013, 3, 104-111. [CrossRef]

29. Jacotet-Navarro, M.; Rombaut, N.; Fabiano-Tixier, A.-S.; Danguien, M.; Bil, A.; Chemat, F. Ultrasound versus microwave as green processes for extraction of rosmarinic, carnosic and ursolic acids from rosemary. Ultrason. Sonochem. 2015, 27, 102-109. [CrossRef] [PubMed]

30. Wu, D.; Gao, T.; Yang, H.; Du, Y.; Li, C.; Wei, L.; Zhou, T.; Lu, J.; Bi, H. Simultaneous microwave/ ultrasonic-assisted enzymatic extraction of antioxidant ingredients from Nitraria tangutorun Bobr. Juice byproducts. Ind. Crops Prod. 2015, 66, 229-238. [CrossRef]

31. Ajuong, E.; Redington, M. Fourier transform infrared analyses of bog and modern oak wood (Quercus petraea) extractives. Wood Sci. Technol. 2004, 38, 181-190. [CrossRef]

32. Grasel, F.S.; Ferrão, M.F.; Wolf, C.R. Development of methodology for identification the nature of the polyphenolic extracts by FTIR associated with multivariate analysis. Spectrochim. Acta A Mol. Biomol. Spectrosc. 2016, 153, 94-101. [CrossRef] [PubMed]

33. Ping, L.; Pizzi, A.; Guo, Z.D.; Brosse, N. Condensed tannins from grape pomace: Characterization by FTIR and MALDI TOF and production of environment friendly wood adhesive. Ind. Crops Prod. 2012, 40, 13-20. [CrossRef]

34. Liu, H.; Shang, J.; Chen, X.; Kamke, F.A.; Guo, K. The influence of thermal-hydro-mechanical processing on chemical characterization of Tsuga heterophylla. Wood Sci. Technol. 2014, 48, 373-392. [CrossRef]

35. Rodríguez-Solana, R.; Daferera, D.J.; Mitsi, C.; Trigas, P.; Polissiou, M.; Tarantilis, P.A. Comparative chemotype determination of Lamiaceae plants by means of GC-MS, FT-IR, and dispersive-Raman spectroscopic techniques and GC-FID quantification. Ind. Crops Prod. 2014, 62, 22-33. [CrossRef]

36. Ribeiro, A.B.; Silva, D.H.S.; Bolzani, V.S. Antioxidant flavonol glycosides from Nectandra grandiflora (Lauraceae). Eclética Química 2002, 27,35-44. [CrossRef]

37. De Rijke, E.; Out, P.; Niessen, W.M.; Ariese, F.; Gooijer, C.; Udo, A.T. Analytical separation and detection methods for flavonoids. J. Chromatogr. A 2006, 1112, 31-63. [CrossRef] [PubMed]

38. Le Quesne, P.W.; Larrahondo, J.E.; Raffauf, R.F. Antitumor plants X Constituents of Nectandra rigida. J. Nat. Prod. 1980, 43, 353-359. [CrossRef] [PubMed]

39. Ross, A.B.; Anastasakis, K.; Kubacki, M.; Jones, J.M. Investigation of the pyrolysis behaviour of brown algae before and after pre-treatment using PY-GC/MS and TGA. J. Anal. Appl. Pyrolysis 2009, 85, 3-10. [CrossRef]

40. Silva, D.T.; Bianchini, N.H.; Muniz, M.F.B.; Heinzmann, B.M.; Labidi, J. Chemical composition and inhibitory effects of Nectandra grandiflora leaves essential oil against wood decay fungi. Drewno 2016, 59, 1-8.

41. Tenorio, C.; Moy, R. Thermogravimetric characteristics, its relation with extractives and chemical properties and combustion characteristics of ten fast-growth species in Costa Rica. Thermochim. Acta 2013, 563, 12-21. [CrossRef]

42. Carballo, T.; Gil, M.V.; Gómez, X.; González-Andrés, F.; Morán, A. Characterization of different compost extracts using Fourier-transform infrared spectroscopy (FTIR) and thermal analysis. Biodegradation 2008, 19, 815-830. [CrossRef] [PubMed]

43. Conceição, M.C.; Junqueira, L.A.; Guedes, S.K.C.; Prado, M.E.T.; de Resende, J.V. Thermal and microstructural stability of a powdered gum derived from Pereskia aculeata Miller leaves. Food Hydrocoll. 2014, 40, 104-114. [CrossRef]

44. Shebani, A.; Van Reenen, A.; Meincken, M. The effect of wood extractives on the thermal stability of different wood species. Thermochim. Acta 2008, 471, 43-50. [CrossRef]

45. Missio, A.L.; Mattos, B.D.; Gatto, D.A.; De Lima, E.A. Thermal analysis of charcoal from fast-growing eucalypt wood: Influence of raw material moisture content. J. Wood Chem. Technol. 2014, 34, 191-201. [CrossRef]

46. Martins, C.R.; Lopes, W.A.; Andrade, J.B. Solubilidade das substâncias orgânicas. Química Nova 2013, 36, 1248-1255. [CrossRef]

47. Re, R.; Pellegrini, N.; Proteggente, A.; Pannala, A.; Yang, M.; Rice-Evans, C. Antioxidant activity applying an improved ABTS radical cation decolorization assay. Free Radic. Biol. Med. 1999, 26, 1231-1237. [CrossRef]

48. Pietta, P. Flavonoids as antioxidants. J. Nat. Prod. 2000, 63, 1035-1042. [CrossRef] [PubMed]

49. Kakkar, S.; Bais, S. A review on protocatechuic acid and its pharmacological potential. ISRN Pharmacol. 2014, 2014, 1-9. [CrossRef] [PubMed] 
50. Wu, P.; Ma, G.; Li, N.; Deng, Q.; Yin, Y.; Huang, R. Investigation of in vitro and in vivo antioxidant activities of flavonoids rich extract from the berries of Rhodomyrtus tomentosa (Ait.) Hassk. Food Chem. 2015, 173, 194-202. [CrossRef] [PubMed]

51. Vundać, V.B.; Brantner, A.H.; Plazibat, M. Content of polyphenolic constituents and antioxidant activity of some Stachys taxa. Food Chem. 2007, 104, 1277-1281. [CrossRef]

52. Magro, A.; Carolino, M.; Bastos, M.; Mexia, A. Efficacy of plant extracts against stored products fungi. Revista Iberoamericana de Micología 2006, 23, 176-178. [CrossRef]

53. Cândido, T.L.N.; Silva, M.R.; Agostini-Costa, T.S. Bioactive compounds and antioxidant capacity of buriti (Mauritia flexuosa L.f.) from the Cerrado and Amazon biomes. Food Chem. 2015, 177, 313-319. [CrossRef] [PubMed]

54. Metrouh-Amir, H.; Duarte, C.M.M.; Maiza, F. Solvent effect on total phenolic contents, antioxidant, and antibacterial activities of Matricaria pubescens. Ind. Crops Prod. 2015, 67, 249-256. [CrossRef]

55. Herrera, R.; Erdocia, X.; Llano-Ponte, R.; Labidi, J. Characterization of hydrothermally treated wood in relation to changes on its chemical composition and physical properties. J. Anal. Appl. Pyrolysis 2014, 107, 256-266. [CrossRef]

56. Dudonné, S.; Vitrac, X.; Coutière, P.; Woillez, M.; Mérillon, J.M. Comparative study of antioxidant properties and total phenolic content of 30 plant extracts of industrial interest using DPPH, ABTS, FRAP, SOD, and ORAC assays. J. Agric. Food Chem. 2009, 57, 1768-1774. [CrossRef] [PubMed]

57. Robles, E.; Salaberria, A.M.; Herrera, R.; Fernandes, S.C.; Labidi, J. Self-bonded composite films based on cellulose nanofibers and chitin nanocrystals as antifungal materials. Carbohydr. Polym. 2016, 144, 41-49. [CrossRef] [PubMed]

Sample Availability: Ethanolic extracts of Nectarina grandiflora leaves are available from the authors.

(C) 2018 by the authors. Licensee MDPI, Basel, Switzerland. This article is an open access article distributed under the terms and conditions of the Creative Commons Attribution (CC BY) license (http:/ / creativecommons.org/licenses/by/4.0/). 